
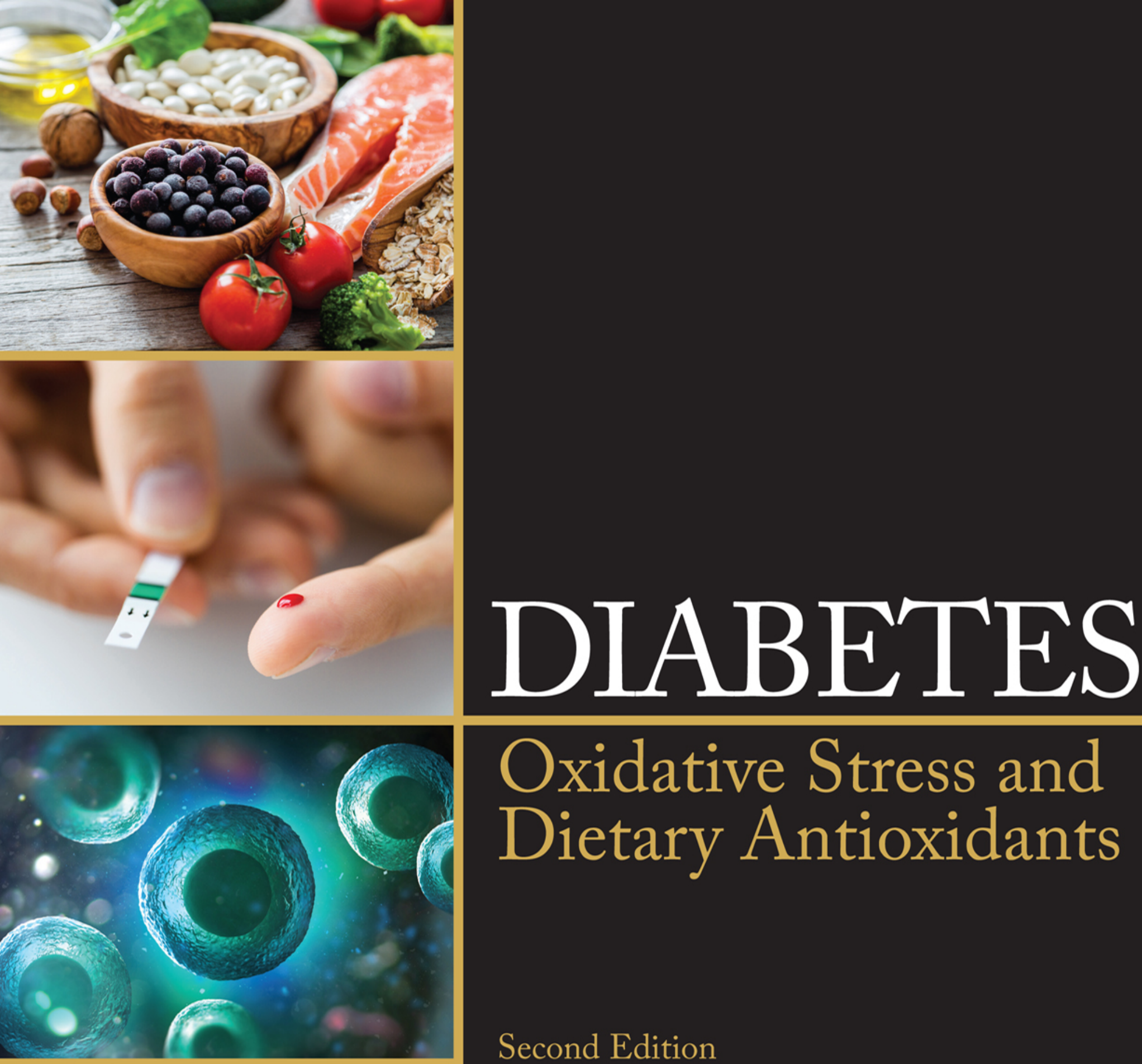

\title{
Oxidative Stress and Dietary Antioxidants
}

Second Edition

Edited by

VICTOR R. PREEDY

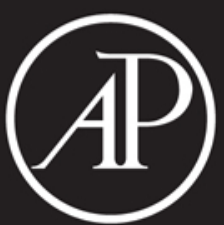




\section{DIABETES}


This page intentionally left blank 


\title{
DIABETES
}

\section{Oxidative Stress and Dietary Antioxidants}

\section{SECOND EDITION}

\author{
Edited by \\ Victor R. PREEDY \\ Department of Nutrition and Dietetics, School of Life Course Sciences, King's College London, \\ London, United Kingdom
}
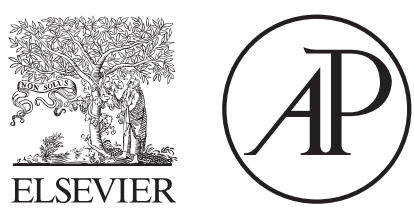
Academic Press is an imprint of Elsevier

125 London Wall, London EC2Y 5 AS, United Kingdom

525 B Street, Suite 1650, San Diego, CA 92101, United States

50 Hampshire Street, 5th Floor, Cambridge, MA 02139, United States

The Boulevard, Langford Lane, Kidlington, Oxford OX ${ }_{5}$ 1GB, United Kingdom

Copyright (C) 2020 Elsevier Inc. All rights reserved.

No part of this publication may be reproduced or transmitted in any form or by any means, electronic or mechanical, including photocopying, recording, or any information storage and retrieval system, without permission in writing from the publisher. Details on how to seek permission, further information about the Publisher's permissions policies and our arrangements with organizations such as the Copyright Clearance Center and the Copyright Licensing Agency, can be found at our website: www.elsevier.com/permissions.

This book and the individual contributions contained in it are protected under copyright by the Publisher (other than as may be noted herein).

\section{Notices}

Knowledge and best practice in this field are constantly changing. As new research and experience broaden our understanding, changes in research methods, professional practices, or medical treatment may become necessary.

Practitioners and researchers must always rely on their own experience and knowledge in evaluating and using any information, methods, compounds, or experiments described herein. In using such information or methods they should be mindful of their own safety and the safety of others, including parties for whom they have a professional responsibility.

To the fullest extent of the law, neither the Publisher nor the authors, contributors, or editors, assume any liability for any injury and/or damage to persons or property as a matter of products liability, negligence or otherwise, or from any use or operation of any methods, products, instructions, or ideas contained in the material herein.

British Library Cataloguing-in-Publication Data

A catalogue record for this book is available from the British Library

Library of Congress Cataloging-in-Publication Data

A catalog record for this book is available from the Library of Congress

ISBN: 978-0-12-815776-3

For Information on all Academic Press publications

visit our website at https://www.elsevier.com/books-and-journals

Publisher: Stacy Masucci

Acquisitions Editor: Tari K. Broderick

Editorial Project Manager: Timothy Bennett

Production Project Manager: Punithavathy Govindaradjane

Cover Designer: Greg Harris

Typeset by MPS Limited, Chennai, India

Working together to grow libraries in developing countries 


\section{Contents}

List of Contributors
Preface

\section{Section I}

\section{Oxidative stress and diabetes}

\section{Oxidative stress markers in diabetes \\ EUGENE BUTKOWSKI}

List of abbreviations

Introduction

Oxidative stress: an overview

Oxidative stress in type 2 diabetes mellitus and cardiovascular disease

Protein kinase $\mathrm{C}$ and reactive oxygen species

Reduced glutathione, glutathione disulfide, and glutathione/ glutathione disulfide

8-Hydroxy-2'-deoxyguanosine

$\mathrm{F}_{2}$-isoprostanes

Malondialdehyde

Whole blood viscosity

Inflammatory biomarkers

The interleukins

Insulin-like growth factor-1

Hyperglycemia and coagulability

Conclusion

Summary points

References

\section{Oxidative stress and diabetic neuropathy HAJUNG CHUN AND YONGSOO PARK}

List of abbreviations

Introduction

Natural history

Hyperglycemia is a crucial cause of diabetic neuropathy

Oxidative stress is a key mediator of diabetic neuropathy

Role of endoplasmic reticulum, microRNAs, and mitochondria in the pathogenesis of diabetic peripheral neuropathy

Normal antioxidant defense mechanisms

Role of interventions in endogenous antioxidant signaling

Role of exercise and diet

Clinical trials of antioxidants

xiii A new antioxidant delivery $\quad 21$

xvii Conclusion 21

Summary points 22

References $\quad 22$

3. Diabetic enteric neuropathy: imbalance between oxidative and antioxidative mechanisms NIKOLETT BÓDI AND MÁRIA BAGYÁNSZKI

3

List of abbreviations

Structure, function, and diabetic state of the enteric nervous system

Gut region-specific oxidative environment and antioxidant capacity under physiological conditions

Diabetes-related changes in the expression of oxidants and antioxidants in the enteric ganglia of different gut segments

Conclusion and perspectives

Summary points

References

4. Hyperglycemia-induced oxidative stress in the development of diabetic foot ulcers

ELIZABETH BOSEDE BOLAJOKO, OLUBAYO MICHAEL AKINOSUN AND AYE AYE KHINE

List of abbreviations

Introduction

Generation of oxidative stress

Hyperglycemia-induced oxidative stress in the development of foot ulcer and delayed wound healing in people with diabetes mellitus

Summary points

References

5. Oxidative stress in diabetic retinopathy

JOSE JAVIER GARCIA-MEDINA, VICENTE ZANON-MORENO, MARIA DOLORES PINAZO-DURAN, ELISA FOULQUIE-MORENO, ELENA RUBIO-VELAZQUEZ, RICARDO P. CASAROLI-MARANO AND MONICA DEL-RIO-VELLOSILLO

List of abbreviations

Histopathology of diabetic retinopathy 49

Oxidative stress mechanisms $\quad 52$

Oxidative stress and diabetic retinopathy 53

Summary points $\quad 55$

References $\quad 56$ 
6. Cerebral ischemia in diabetics and oxidative stress

SUNJOO CHO, PERRY FUCHS, DEEPANEETA SARMAH, HARPREET KAUR, PALLAB BHATTACHARYA

AND KUNJAN R. DAVE

List of abbreviations

Introduction

Conclusion

Summary points

References

\section{Gingival wound healing in diabetes}

PRIMA BURANASIN, KENGO IWASAKI AND KOJI MIZUTANI

List of abbreviations

Introduction

In vitro study

In vivo study

Clinical findings

Conclusion

Summary points

References

8. Oxidative stress in gestational diabetes mellitus

PHUDIT JATAVAN

List of abbreviations

Introduction

Oxidative stress in gestational diabetes mellitus

Diabetic embryopathy

Oxidative stress in the amniotic fluid and placenta in gestational diabetes mellitus patients

Oxidative stress level in fetal circulation in pregnancy affected with gestational diabetes mellitus

Role of antioxidant supplements in gestational diabetes mellitus

Fetal and maternal outcomes

Summary points

References

\section{Epigenetics, oxidative states and diabetes}

ELEONORA SCACCIA, ANTONELLA BORDIN, CARMELA RITA BALISTRERI AND ELENA DE FALCO

List of abbreviations

Introduction

Epigenetics controls physiological mechanisms modulated by redox states

The role of mitochondria: the hotbed of redox states

MicroRNAs: the epigenetic regulators between redox states and diabetes

Diabetes changes the redox states through epigenetics

Summary points

References
10. MicroRNAs linking oxidative stress and

59 diabetes

JULIAN FRIEDRICH AND GUIDO KRENNING

List of abbreviations $\quad 97$

Introduction $\quad 97$

59 MicroRNA biogenesis and function 98

59 The influence of oxidative stress on microRNA biogenesis 98

66 The influence of microRNAs on oxidative stress in diabetes 99

66 RedoximiRs in diabetes 101

67 MicroRNAs and oxidative stress in specific diabetic complications

102

102

104

104

104

104

105

\section{Conclusion and perspective}

Summary points

References

11. Polymorphism of MnSOD 47C/T

antioxidant enzymes and type 1 diabetes

A. EDDAIKRA AND C. TOUIL BOUKOFFA

List of abbreviations

Introduction

Antioxidant defenses

79 Gene of superoxide dismutase 2

MnSOD 47C/T polymorphism

Minor allele of MnSOD 47C/T

109

110

79 Role of the manganese

111

111

111

80 Mitochondrial production of reactive oxygen species

80 Regulation of the superoxide dismutase 2 gene

Concept of adaptative response

81 Oxidation of proteins

Conclusion

82 Summary points

References

82 Further reading

12. Sodium-glucose cotransporter 2 inhibitors, diabetes, and oxidative stress

SEBASTIAN STEVEN, KATIE FRENIS, MATTHIAS OELZE, KSENIJA

VUJACIC-MIRSKI, MARIA TERESA BAYO JIMENEZ,

SANELA KALINOVIC, SWENJA KRÖLLER-SCHÖN,

THOMAS MÜNZEL AND ANDREAS DAIBER

List of abbreviations

87 Prevalence and incidence of diabetes, treatment options as well as its contribution to cardiovascular disease and mortality

Pathomechanisms of diabetes

Experimental studies in type 1 and type 2 diabetic rats with sodium-glucose cotransporter 2 inhibitor therapy 120

Summary points $\quad 125$

93 Acknowledgments 126

94 Conflicts of interest 126

94 References 126 
13. NADPH oxidases, nuclear factor kappa B, NF-E2-related factor2, and oxidative stress in diabetes

ANDRZEJ BERĘSEWICZ

List of abbreviations

Introduction

Cellular signaling via redox modification of target proteins

Vascular sources of reactive oxygen and nitrogen species

Nuclear factor kappa B and NF-E2-related factor2 are controlled by reactive oxygen species and control reactive oxygen species

The organization of redox-signaling networks in the vasculature

NADPH oxidases, nuclear factor kappa B, NF-E2-related factor2, and endothelial form of nitric oxide synthase in diabetes

Summary points

References

14. Antioxidant properties of drugs used in type 2 diabetes management

SIU-WAI CHOI AND CYRUS KIN-CHUN HO

List of abbreviations

Introduction

Conclusion

Summary points

References

\section{Section II}

\section{Antioxidants and diabetes}

15. Antioxidants, oxidative stress, and preeclampsia in diabetes

ARPITA BASU AND TIMOTHY J. LYONS

List of abbreviations

Introduction

Oxidative stress and antioxidant status in pregnancies complicated by type 1 diabetes mellitus and gestational diabetes mellitus

Oxidative stress and antioxidant status in preeclampsia

Antioxidant supplementation in preeclampsia and gestational diabetes mellitus: findings from clinical studies Summary points

References

Introduction: oxidative stress in diabetes

Docosahexaenoic acid

Docosahexaenoic acid and oxidative stress

163

Docosahexaenoic acid derivatives: a new frontier

164

Docosahexaenoic acid and oxidative stress in the brain

Summary points

165

166

References

166

17. Antioxidant supplementation in diabetic retinopathy

JOSE JAVIER GARCIA-MEDINA, ELENA RUBIO-VELAZQUEZ, RICARDO P. CASAROLI-MARANO, VICENTE ZANON-MORENO, MARIA DOLORES PINAZO-DURAN, ELISA FOULQUIE-MORENO AND MONICA DEL-RIO-VELLOSILLO

List of abbreviations

Introduction

169

In vitro studies

170

Animal studies

Clinical studies

Final comments and future directions

References

DENNIS S. AROKOYO AND OLUBAYODE BAMIDELE

List of abbreviations

Introduction

Beneficial effects of Basella alba in diabetes mellitus

References

19. Bauhinia vahlii and antioxidant potential in diabetes

ENGY A. MAHROUS AND MOHAMMED M. NOOH

List of abbreviations

Introduction

Conclusion

Summary points

200

References

16. Antioxidative component of docosahexaenoic acid in the brain in diabetes

20. Carnosine, pancreatic protection, and oxidative stress in type 1 diabetes

VITALE MICELI AND PIER GIULIO CONALDI

Introduction 203

Conclusion 209

Summary points 209

161 References $\quad 210$

List of abbreviations 


\section{Centella asiatica: its potential for the} treatment of diabetes

AYODEJI B. OYENIHI, BLESSING O. AHIANTE, OMOLOLA R. OYENIHI AND BUBUYA MASOLA

List of abbreviations

Introduction

Oxidative stress, diabetes, and diabetic complications

Conventional antidiabetic drugs or traditional medicines?

Antioxidant and antidiabetic qualities of Centella asiatica

Conclusion

References

22. Effects of Chrysanthemi Flos against diabetes and its complications related to insulin resistance

SUNG-JIN KIM

List of abbreviations

Diabetes

Chrysanthemi Flos

Effects of Chrysanthemi Flos on diabetes and its complications 225

Effect of Chrysanthemi Flos on insulin resistance

Effect of Chrysanthemi Flos on other biological activities

Chemical constituents of Chrysanthemi Flos and their activities

Toxic effects of Chrysanthemi Flos

Conclusion

Summary points

References

\section{Cinnamic acid as a dietary antioxidant} in diabetes treatment

HATICE GÜL ANLAR

List of abbreviations

Introduction

Diabetes mellitus and oxidative stress

Chemistry of cinnamic acid

Dietary source and dietary-intake levels of cinnamic acid

Pharmacokinetic properties of cinnamic acid

Antioxidant activity of cinnamic acid

Antidiabetic effects of cinnamic acid

Conclusion

Summary points

References

24. Cranberry, oxidative stress, inflammatory markers, and insulin sensitivity: a focus on intestinal microbiota

ANA SOFÍA MEDINA-LARQUÉ, YVES DESJARDINS

AND HÉLÈNE JACQUES

List of abbreviations

Introduction

Cranberry and oxidative stress and systemic inflammation
Cranberry and gut microbiota homeostasis

Cranberry, enhanced intestinal barrier integrity, and decreased metabolic endotoxemia

Cranberry, glucose metabolism, and insulin sensitivity

Conclusion

250

Summary points

251

References

25. Glutamine and its antioxidative potentials in diabetes

SUNG-LING YEH, YAO-MING SHIH AND MING-TSAN LIN

List of abbreviations $\quad 255$

Introduction to glutamine $\quad 255$

Cellular functions of glutamine 255

Antioxidative and antiinflammatory properties of glutamine 256

Hyperglycemia-induced oxidative stress and its associated complications

Effects of glutamine on glucose homeostasis and insulin sensitivity

Mechanisms of glutamine in attenuating hyperglycemia-induced oxidative stress and inflammation

Conclusion

Summary points

References

\section{The antioxidant potential of Lactarius}

deterrimus in diabetes

JELENA ARAMBAŠIĆ JOVANOVIĆ, MIRJANA MIHAILOVIĆ, SVETLANA DINIĆ, NEVENA GRDOVIĆ, ALEKSANDRA USKOKOVIĆ, GORAN POZNANOVIĆ AND MELITA VIDAKOVIĆ

List of abbreviations

Introduction

Characteristic of the Lactarius species

Mechanisms and pathways underlying diabetes development

Systemic antioxidant and antiglycation effect of the Lactarius deterrimus extract in vivo

Protective effects of the Lactarius deterrimus extract on pancreatic islets in vivo

Protective effects of the Lactarius deterrimus extract on hepatorenal injury in vivo

Summary points

References

245 27. Limonene and ursolic acid in the treatment of diabetes

MERVE BACANLI

Diabetes 
General information about limonene

Diabetes and limonene

General information about ursolic acid

Diabetes and ursolic acid

Conclusion

Summary points

References

28. Palm oil: its antioxidant potential in diabetes mellitus

TOYIN DORCAS ALABI, FOLORUNSO ADEWALE OLABIYI AND OLUWAFEMI OMONIYI OGUNTIBEJU

List of abbreviations

Introduction

Summary points

Recommendations and further studies

References

\section{Quercetin and antioxidant potential in} diabetes

FRANCIS I. ACHIKE AND DHARMANI D. MURUGAN

List of abbreviations

Introduction

Historic background

Oxidative stress in the etiopathogenesis of diabetes mellitus

The oxygen paradox

Sources of oxidative stress

Mitochondria

NADPH oxidases

Xanthine oxidase

Polyol pathway

Hexosamine pathway

AGEs and RAGEs

Antioxidants

Conclusion

Summary points

References

Further reading

30. Resveratrol in diabetes: benefits against oxidative stress in male reproduction

SANDRA MARIA MIRAGLIA, JOANA NOGUÈRES SIMAS,

TALITA BIUDE MENDES AND VANESSA VENDRAMINI

List of abbreviations

Introduction

Summary points

References

31. Salvia hispanica L. and its therapeutic role in a model of insulin resistance

MARÍA DEL ROSARIO FERREIRA, SILVINA ALVAREZ, PAOLA ILLESCA, MARÍA SOFÍA GIMÉNEZ AND YOLANDA B. LOMBARDO

List of abbreviations

Introduction

Overview of Salvia hispanica L.

316

Application to health promotion and disease prevention or improvement

Effects of dietary Salvia hispanica L. (Salba) on oxidative stress, adipose tissue dysfunction, dyslipidemia, and insulin resistance

Summary points

References

32. Spirulina platensis, oxidative stress, and diabetes

AREZKI BITAM AND OURIDA AISSAOUI

285

285

289

289

289

293

293

293

294

294

294

294

294

295

295

295

295

295

299

299

299

302

303

303

303

312

312

35. Protective role of taurine and structurally related compounds against diabetes-induced oxidative stress

CESAR A. LAU-CAM

List of abbreviations

List of abbreviations $\quad 333$

Introduction $\quad 333$

stress and diabetes

Impact of statins on oxidative stress $\quad 335$

Diabetic macrovascular disease: clinical evidence $\quad 337$

Diabetic microvascular disease: clinical evidence 338

Summary and future directions $\quad 338$

Summary points $\quad 338$

34. Nanoparticle formulation of Syzygium cumini, antioxidants, and diabetes

PAULA E.R. BITENCOURT

$\begin{array}{ll}\text { Summary points } & 349 \\ \text { References } & 349\end{array}$ 
Introduction

TAU and diabetes

TAU, diabetes, and the cardiovascular system

TAU, diabetes, and erythrocytes

TAU, diabetes, and the eye

TAU, diabetes, and the kidney

TAU, diabetes, and the liver

TAU, diabetes, and the nervous system

Conclusions

Summary points

References

36. Taurine and cardiac oxidative stress in diabetes

JOYDEEP DAS, SUMIT GHOSH AND PARAMES C. SIL

List of abbreviations

Introduction

Diabetes-induced oxidative stress

The role of mitochondria in ROS production

Advanced glycation end-products (AGE)-mediated ROS production

The role of NADPH oxidase in ROS production

The role of CaMKII in ROS production

The role of fatty acids in ROS production

The role of the polyol pathway in ROS production

The role of $\mathrm{Nrf2}$ in ROS production

The role of xanthine oxidase in ROS production

The role of increased hexosamine flux in ROS production

The role of PKC activation in ROS production

The role of angiotensin II activation in ROS production

Endogenous antioxidant mechanisms

The beneficial role of taurine

Depletion of taurine in the myocardium due to diabetic cardiomyopathy

Mechanisms of the antihyperglycemic action of taurine

The antioxidant mechanism of taurine against cardiac oxidative stress under diabetic conditions

Combinatorial therapies involving taurine for the treatment of cardiac oxidative stress

Summary points

References

37. Vitamins, antioxidants, and type 2 diabetes

FERNANDA S. TONIN, HELENA H. BORBA, ASTRID WIENS, FERNANDO FERNANDEZ-LLIMOS AND ROBERTO PONTAROLO

List of abbreviations

Introduction

Free radicals, oxidative stress, and diabetes

Antioxidants and their role in type 2 diabetes

Vitamins and antioxidant mechanisms

Vitamin supplementation in type 2 diabetes: clinical evidence

Conclusions

Summary points

References
38. Vitamin D, oxidative stress, and diabetes: crossroads for new therapeutic approaches

BAHAREH NIKOOYEH, RAZIEH ANARI

AND TIRANG R. NEYESTANI

List of abbreviations $\quad 385$

Introduction $\quad 385$

Vitamin D 386

Oxidative stress in diabetes: development and complications $\quad 388$

Vitamin D and diabetes 389

Vitamin D as an antioxidant $\quad 390$

Antioxidant effect of vitamin $\mathrm{D}$ in diabetes: direct versus indirect effect

Conclusion $\quad 392$

Summary points $\quad 393$

References 394

39. Vitamin E, high-density lipoproteins, and vascular protection in diabetes

TINA COSTACOU, JOSHUA B. WIENER, ELLIOT M. BERINSTEIN AND ANDREW P. LEVY

List of abbreviations

Introduction $\quad 397$

The haptoglobin protein $\quad 398$

High-density lipoproteins 400

Haptoglobin and high-density lipoprotein 401

Vascular protection by vitamin E 401

Summary/future directions/conclusions $\quad 403$

Summary points 404

References 404

\section{Section III}

\section{Techniques and resources}

40. Superoxide dismutase as a measure of antioxidant status and its application to diabetes

FELIX OMORUYI, JEAN SPARKS, DEWAYNE STENNETT AND LOWELL DILWORTH

Introduction

Oxidative stress in diabetes

Complications associated with diabetes 411

Oxidative damage

Oxidative defense system

Superoxide dismutase

Superoxide dismutase activity determination $\quad 414$

$\begin{array}{ll}\text { Pyrogallol autoxidation method } & 414\end{array}$

Calculation of SOD activity 414

In-Gel assay 414

Early detection and treatment of diabetes $\quad 414$

Summary points $\quad 416$

References 416 
41. Recommended resources for diabetes, oxidative stress, and dietary antioxidants

RAJKUMAR RAJENDRAM, VINOOD B. PATEL AND VICTOR R. PREEDY

Introduction

Resources
Acknowledgements

419 Summary points

References

Index
421

421

422

423 
This page intentionally left blank 


\section{List of Contributors}

Francis I. Achike Office of Medical Education, College of Medicine, Health Science Center, Texas A\&M University, Bryan, TX, United States

Blessing O. Ahiante Hypertension in Africa Research Team (HART) Faculty of Health Sciences, North-West University, Potchefstroom, South Africa

Ourida Aissaoui Institute of Science and Applied Techniques, University of Saad Dahleb Blida 1, Blida, Algeria

Olubayo Michael Akinosun Department of Chemical Pathology, Faculty of Basic Medical Sciences, College of Medicine, University of Ibadan, Ibadan, Nigeria

Toyin Dorcas Alabi Phytomedicine and Phytochemistry Group, Oxidative Stress Research Centre, Department of Biomedical Sciences, Faculty of Health and Wellness Sciences, Cape Peninsula University of Technology, Bellville, South Africa

Silvina Alvarez Biological Chemistry Laboratory, Faculty of Chemistry, Biochemistry and Pharmacy, National University of San Luis, San Luis, Argentina; IMIBIO-SL, CONICET, Argentina

Razieh Anari National Nutrition and Food Technology Research Institute (NNFTRI), Faculty of Nutrition Science and Food Technology, Shahid Beheshti University of Medical Sciences, Tehran, Iran

Hatice Gül Anlar Department of Pharmaceutical Toxicology, Faculty of Pharmacy, Zonguldak Bulent Ecevit University, Zonguldak, Turkey

Emma Arnal Faculty of Health Sciences, European University of Valencia, Valencia, Spain

Dennis S. Arokoyo Department of Physiology, Faculty of Basic Medical and Health Sciences, College of Health Sciences, Bowen University, Iwo, Nigeria

Merve Bacanlı Gülhane Faculty of Pharmacy, Department of Pharmaceutical Toxicology, University of Health Sciences, Ankara, Turkey

Mária Bagyánszki Department of Physiology, Anatomy and Neuroscience, Faculty of Science and Informatics, University of Szeged, Szeged, Hungary

Carmela Rita Balistreri Department of Biomedicine, Neuroscience and Advanced Diagnostics (Bi.N.D.), University of Palermo, Palermo, Italy

Olubayode Bamidele Department of Physiology, Faculty of Basic Medical and Health Sciences, College of Health Sciences, Bowen University, Iwo, Nigeria
Arpita Basu Department of Kinesiology and Nutrition Sciences, School of Allied Health Sciences, University of Nevada at Las Vegas, Las Vegas, NV, United States

Andrzej Beręsewicz Department of Clinical Physiology, Postgraduate Medical School, Warsaw, Poland

Elliot M. Berinstein Ruth and Bruce Rappaport Faculty of Medicine, Technion Israel Institute of Technology, Haifa, Israel

Pallab Bhattacharya Stroke Research and Therapeutics Laboratory, Department of Pharmacology and Toxicology, National Institute of Pharmaceutical Education and Research (NIPER), Ahmedabad, India

Arezki Bitam Department of Food Technology, Laboratory of Food Technology and Human Nutrition, Agronomic Higher National School, El-Harrach, Algeria

Paula E.R. Bitencourt Departamento de Análises Clínicas e Toxicológicas, Centro de Ciências da Saúde, Universidade Federal de Santa Maria (UFSM), Santa Maria, RS, Brazil; Programa de Pós-Graduação em Ciências Biológicas: Farmacologia e Terapêutica, Universidade Federal do Rio Grande do Sul (UFRGS), Porto Alegre, Brazil

Nikolett Bódi Department of Physiology, Anatomy and Neuroscience, Faculty of Science and Informatics, University of Szeged, Szeged, Hungary

Elizabeth Bosede Bolajoko Department of Chemical Pathology, Faculty of Basic Medical Sciences, College of Medicine, University of Ibadan, Ibadan, Nigeria

Helena H. Borba Department of Pharmacy, Federal University of Paraná, Curitiba, Brazil

Antonella Bordin Department of Medical-Surgical Sciences and Biotechnologies, Faculty of Pharmacy and Medicine, Sapienza University of Rome, Latina, Italy

Prima Buranasin Department of Periodontology, Graduate School of Medical and Dental Sciences, Tokyo Medical and Dental University (TMDU), Tokyo, Japan;

Department of Conservative Dentistry and Prosthodontics, Faculty of Dentistry, Srinakharinwirot University, Bangkok, Thailand

Eugene Butkowski School of Community Health, Charles Sturt University, Thurgoona, NSW, Australia

Ricardo P. Casaroli-Marano Department of Surgery and Hospital Clínic de Barcelona, University of Barcelona, Barcelona, Spain; Institute of Biomedical Research (IIBSant Pau) and Banc de Sang i Texits (BST), Barcelona, Spain 
Sunjoo Cho Peritz Scheinberg Cerebral Vascular Disease Research Laboratories, Department of Neurology, Leonard M. Miller School of Medicine, University of Miami, Miami, FL, United States

Siu-Wai Choi Oral and Maxillofacial Surgery, The University of Hong Kong, Hong Kong SAR, P.R. China

Hajung Chun Department of Radiation Oncology and Bioengineering, Hanyang University College of Medicine and Engineering, Seoul, South Korea

Pier Giulio Conaldi Department of Research, IRCCSISMETT (Istituto Mediterraneo per i Trapianti e Terapie ad alta specializzazione), Palermo, Italy

Tina Costacou University of Pittsburgh, Pittsburgh, PA, United States

Andreas Daiber Center for Cardiology, Cardiology I, University Medical Center at the Johannes Gutenberg University Mainz, Mainz, Germany

Joydeep Das School of Chemistry, Faculty of Basic Sciences, Shoolini University, Solan, Himachal Pradesh, India

Kunjan R. Dave Peritz Scheinberg Cerebral Vascular Disease Research Laboratories, Department of Neurology, Leonard M. Miller School of Medicine, University of Miami, Miami, FL, United States

Elena De Falco Department of Medical-Surgical Sciences and Biotechnologies, Faculty of Pharmacy and Medicine, Sapienza University of Rome, Latina, Italy; Mediterranea Cardiocentro-Napoli, Naples, Italy

Monica del-Rio-Vellosillo Department of Anesthesiology, University Hospital La Arrixaca, Murcia, Spain

Yves Desjardins Institute of Nutrition and Functional Foods, Quebec, QC, Canada

Lowell Dilworth Department of Pathology, The University of the West Indies, Mona, Jamaica

Svetlana Dinić Institute for Biological Research, National Institute of Republic of Serbia, University of Belgrade, Belgrade, Serbia

A. Eddaikra Departement of Cellular Biology and Physiology, Faculty of Nature and Life, University Saad Dahlab, Blida, Algeria

Fernando Fernandez-Llimos Research Institute for Medicines (iMed. ULisboa), Department of Social Pharmacy, Faculty of Pharmacy, University of Lisbon, Lisbon, Portugal

María del Rosario Ferreira Department of Biochemistry, Faculty of Biochemistry and Biological Sciences, National University of Litoral, University City, Santa Fe, Argentina; CONICET, Argentina

Elisa Foulquie-Moreno Department of Ophthalmology, General University Hospital Morales Meseguer, Murcia, Spain

Katie Frenis Center for Cardiology, Cardiology I, University Medical Center at the Johannes Gutenberg University Mainz, Mainz, Germany
Julian Friedrich 5th Medical Department, Section of Endocrinology, Medical Faculty Mannheim, University of Heidelberg, Mannheim, Germany

Perry Fuchs Peritz Scheinberg Cerebral Vascular Disease Research Laboratories, Department of Neurology, Leonard M. Miller School of Medicine, University of Miami, Miami, FL, United States

Jose Javier Garcia-Medina Department of Ophthalmology, General University Hospital Morales Meseguer, Murcia, Spain; Department of Ophthalmology and Optometry, School of Medicine, University of Murcia, Murcia, Spain; Ophthalmic Research Unit Santiago Grisolia/FISABIO and Cellular and Molecular Ophthalmobiology Group, University of Valencia, Valencia, Spain

Sumit Ghosh Division of Molecular Medicine, Bose Institute, Kolkata, India

María Sofía Giménez Biological Chemistry Laboratory, Faculty of Chemistry, Biochemistry and Pharmacy, National University of San Luis, San Luis, Argentina; IMIBIO-SL, CONICET, Argentina

Nevena Grdović Institute for Biological Research, National Institute of Republic of Serbia, University of Belgrade, Belgrade, Serbia

Cyrus Kin-chun Ho Oral and Maxillofacial Surgery, The University of Hong Kong, Hong Kong SAR, P.R. China; Faculty of Veterinary and Agricultural Sciences, The University of Melbourne, Melbourne, VIC, Australia

Paola Illesca Department of Biochemistry, Faculty of Biochemistry and Biological Sciences, National University of Litoral, University City, Santa Fe, Argentina; CONICET, Argentina

Kengo Iwasaki Institute of Dental Research, Osaka Dental University, Osaka, Japan

Hélène Jacques School of Nutrition, Paul-Comtois Building, Laval University, Quebec, QC, Canada

Phudit Jatavan Division of Maternal - Fetal Medicine, Department of Obstetrics and Gynecology, Chiang Mai University, Chiang Mai, Thailand

Maria Teresa Bayo Jimenez Center for Cardiology, Cardiology I, University Medical Center at the Johannes Gutenberg University Mainz, Mainz, Germany

Siv Johnsen-Soriano Faculty of Health Sciences, European University of Valencia, Valencia, Spain

Jelena Arambašić Jovanović Institute for Biological Research, National Institute of Republic of Serbia, University of Belgrade, Belgrade, Serbia

Sanela Kalinovic Center for Cardiology, Cardiology I, University Medical Center at the Johannes Gutenberg University Mainz, Mainz, Germany

Harpreet Kaur Stroke Research and Therapeutics Laboratory, Department of Pharmacology and Toxicology, National Institute of Pharmaceutical Education and Research (NIPER), Ahmedabad, India 
Aye Aye Khine Discipline of Chemical Pathology, Faculty of Medicine and Health Sciences, Stellenbosch University, Tygerberg Academic Laboratory, National Health Service Cape Town, South Africa

Sung-Jin Kim Department of Pharmacology and Toxicology, School of Dentistry, Kyung Hee University, Seoul, Republic of Korea

Guido Krenning Laboratory for Cardiovascular Regenerative Medicine (CAVAREM), Department of Pathology and Medical Biology, University Medical Center Groningen, University of Groningen, Groningen, The Netherlands

Swenja Kröller-Schön Center for Cardiology, Cardiology I, University Medical Center at the Johannes Gutenberg University Mainz, Mainz, Germany

Cesar A. Lau-Cam Department of Pharmaceutical Sciences, College of Pharmacy and Health Sciences, St. John's University, Jamaica, NY, United States

Andrew P. Levy Ruth and Bruce Rappaport Faculty of Medicine, Technion Israel Institute of Technology, Haifa, Israel

Ming-Tsan Lin Department of Surgery, National Taiwan University Hospital, Taipei, Taiwan, ROC

Yolanda B. Lombardo Department of Biochemistry, Faculty of Biochemistry and Biological Sciences, National University of Litoral, University City, Santa Fe, Argentina; CONICET, Argentina

Daniel López-Malo Faculty of Health Sciences, European University of Valencia, Valencia, Spain

Timothy J. Lyons Division of Endocrinology, Medical University of South Carolina, Charleston, SC, United States

Engy A. Mahrous Department of Pharmacognosy, Faculty of Pharmacy, Cairo University, Cairo, Egypt,

Bubuya Masola Discipline of Biochemistry School of Life Sciences, University of KwaZulu-Natal, Durban, South Africa

Ana Sofía Medina-Larqué Institute of Nutrition and Functional Foods, Quebec, QC, Canada; School of Nutrition, Paul-Comtois Building, Laval University, Quebec, QC, Canada

Talita Biude Mendes Laboratory of Developmental Biology, Department of Morphology and Genetics, Federal University of Sao Paulo, Brazil

Vitale Miceli Department of Research, IRCCS-ISMETT (Istituto Mediterraneo per i Trapianti e Terapie ad alta specializzazione), Palermo, Italy

Mirjana Mihailović Institute for Biological Research, National Institute of Republic of Serbia, University of Belgrade, Belgrade, Serbia

Sandra Maria Miraglia Laboratory of Developmental Biology, Department of Morphology and Genetics, Federal University of Sao Paulo, Brazil
Maria Miranda Department of Biomedical Sciences, Faculty of Health Sciences, CEU University Cardenal Herrera, Moncada, Spain

Koji Mizutani Department of Periodontology, Graduate School of Medical and Dental Sciences, Tokyo Medical and Dental University (TMDU), Tokyo, Japan

Thomas Münzel Center for Cardiology, Cardiology I, University Medical Center at the Johannes Gutenberg University Mainz, Mainz, Germany

Jonathan R. Murrow Department of Medicine, Augusta University - University of Georgia Medical Partnership, Athens, GA, United States

Dharmani D. Murugan Department of Pharmacology, Faculty of Medicine, University of Malaya, Kuala Lumpur, Malaysia

Tirang R. Neyestani National Nutrition and Food Technology Research Institute (NNFTRI), Faculty of Nutrition Science and Food Technology, Shahid Beheshti University of Medical Sciences, Tehran, Iran; Laboratory of Nutrition Research, National Nutrition and Food Technology Research Institute (NNFTRI), Arghavan Gharbi, Shahrak Qods (Gharb), Tehran, Iran

Bahareh Nikooyeh National Nutrition and Food Technology Research Institute (NNFTRI), Faculty of Nutrition Science and Food Technology, Shahid Beheshti University of Medical Sciences, Tehran, Iran

Mohammed M. Nooh Department of Biochemistry, Faculty of Pharmacy, Cairo University, Cairo, Egypt

Matthias Oelze Center for Cardiology, Cardiology I, University Medical Center at the Johannes Gutenberg University Mainz, Mainz, Germany

Oluwafemi Omoniyi Oguntibeju Phytomedicine and Phytochemistry Group, Oxidative Stress Research Centre, Department of Biomedical Sciences, Faculty of Health and Wellness Sciences, Cape Peninsula University of Technology, Bellville, South Africa

Folorunso Adewale Olabiyi Phytomedicine and Phytochemistry Group, Oxidative Stress Research Centre, Department of Biomedical Sciences, Faculty of Health and Wellness Sciences, Cape Peninsula University of Technology, Bellville, South Africa; Department of Medical Laboratory Science, College of Medicine and Health Sciences, Afe Babalola University, Ado-Ekiti, Nigeria

Felix Omoruyi Department of Life Sciences, Texas A\&M University-Corpus Christi, Corpus Christi, TX, United States

Ayodeji B. Oyenihi Functional Foods Research Unit, Department of Biotechnology and Consumer Science, Faculty of Applied Science, Cape Peninsula University of Technology, Bellville, South Africa

Omolola R. Oyenihi Department of Biochemistry Faculty of Science, Stellenbosch University, Stellenbosch, South Africa 
Yongsoo Park Department of Radiation Oncology and Bioengineering, Hanyang University College of Medicine and Engineering, Seoul, South Korea; Health Insurance Review and Assessment Service, Uijeongbu, South Korea

Vinood B. Patel School of Life Sciences, University of Westminster, London, United Kingdom

Maria Dolores Pinazo-Duran Ophthalmic Research Unit Santiago Grisolia/FISABIO and Cellular and Molecular Ophthalmobiology Group, University of Valencia, Valencia, Spain

Roberto Pontarolo Department of Pharmacy, Federal University of Paraná, Curitiba, Brazil

Goran Poznanović Institute for Biological Research, National Institute of Republic of Serbia, University of Belgrade, Belgrade, Serbia

Victor R. Preedy Department of Nutrition and Dietetics, School of Life Course Sciences, King's College London, London, United Kingdom

Rajkumar Rajendram College of Medicine, King Saud bin Abdulaziz University for Health Sciences, Riyadh, Saudi Arabia; Department of Nutrition and Dietetics, School of Life Course Sciences, King's College London, London, United Kingdom

Francisco J. Romero Faculty of Health Sciences, European University of Valencia, Valencia, Spain; Requena General Hospital, Requena, Generalitat Valenciana, Spain

Elena Rubio-Velazquez Department of Ophthalmology, General University Hospital Morales Meseguer, Murcia, Spain

Deepaneeta Sarmah Stroke Research and Therapeutics Laboratory, Department of Pharmacology and Toxicology, National Institute of Pharmaceutical Education and Research (NIPER), Ahmedabad, India

Eleonora Scaccia Department of Medical-Surgical Sciences and Biotechnologies, Faculty of Pharmacy and Medicine, Sapienza University of Rome, Latina, Italy

Yao-Ming Shih Department of Surgery, Cathay General Hospital, Taipei, Taiwan, ROC

Parames C. Sil Division of Molecular Medicine, Bose Institute, Kolkata, India

Joana Noguères Simas Laboratory of Developmental Biology, Department of Morphology and Genetics, Federal University of Sao Paulo, Brazil
Jean Sparks Department of Life Sciences, Texas A\&M University-Corpus Christi, Corpus Christi, TX, United States

Dewayne Stennett Department of Basic Medical Sciences, Biochemistry Section, The University of the West Indies, Mona, Jamaica

Sebastian Steven Center for Cardiology, Cardiology I, University Medical Center at the Johannes Gutenberg University Mainz, Mainz, Germany

Fernanda S. Tonin Pharmaceutical Sciences Postgraduate Program, Federal University of Paraná, Curitiba, Brazil

C. Touil Boukoffa Laboratory of Cellular and Molecular Biology, Cyokines and NO Synthases Group, Faculty of Biological Sciences, University of Science and Technology Houari Boumediene (USTHB), Algiers, Algeria

Aleksandra Uskoković Institute for Biological Research, National Institute of Republic of Serbia, University of Belgrade, Belgrade, Serbia

Vanessa Vendramini Laboratory of Developmental Biology, Department of Morphology and Genetics, Federal University of Sao Paulo, Brazil

Melita Vidaković Institute for Biological Research, National Institute of Republic of Serbia, University of Belgrade, Belgrade, Serbia

Ksenija Vujacic-Mirski Center for Cardiology, Cardiology I, University Medical Center at the Johannes Gutenberg University Mainz, Mainz, Germany

Joshua B. Wiener Ruth and Bruce Rappaport Faculty of Medicine, Technion Israel Institute of Technology, Haifa, Israel

Astrid Wiens Department of Pharmacy, Federal University of Paraná, Curitiba, Brazil

Sung-Ling Yeh School of Nutrition and Health Sciences, College of Nutrition, Taipei Medical University, Taipei, Taiwan, ROC

Vicente Zanon-Moreno Ophthalmic Research Unit Santiago Grisolia/FISABIO and Cellular and Molecular Ophthalmobiology Group, University of Valencia, Valencia, Spain; Universidad Europea de Valencia, Valencia, Spain 


\section{Preface}

In the past few decades there have been major advances in our understanding of the etiology of disease and its causative mechanisms. Increasingly it is becoming evident that free radicals are contributory agents: either to initiate or propagate pathologies or to create an overall cellular and metabolic imbalance. Furthermore, a reduced intake of dietary antioxidants can also lead to an increased risk of specific diseases. On the other hand, there is abundant evidence that naturally occurring antioxidants can be used to prevent, ameliorate, or impede such disease risks. The science of oxidative stress and free radical biology is rapidly advancing and new approaches include examining the roles of genetics and molecular biology.

However, most textbooks on dietary antioxidants do not have material on the fundamental biology of free radicals, especially their molecular and cellular effects on pathology. They also fail to include material on the nutrients and foods that contain antioxidative activity. In contrast, most books on free radicals and disease have little or no text on the usage of natural antioxidants.

In the present volume Diabetes: Oxidative Stress and Dietary Antioxidants, Second Edition, holistic information is imparted within a structured format of three main sections.

Section I: Oxidative Stress and Diabetes

Section II: Antioxidants and Diabetes

Section III: Techniques and Resources

Section I: Oxidative Stress and Diabetes covers the basic biology of oxidative stress from molecular biology to physiological pathology. In Section II: Antioxidants and Diabetes we describe agents and their actions. The caveat of these chapters in Section II is that there needs to be further in-depth analysis of these components in terms of safety and efficacy as some material is exploratory or preclinical. A cautionary and critical approach is needed. Nevertheless, the material in Section II can provide the framework for further indepth analysis or studies. This would be via welldesigned clinical trials or via the analysis of pathways, mechanisms, and components in order to devise new therapeutic strategies. Section III: Techniques and Resources provides a practical source of information. Both preclinical and clinical studies are embraced using an evidence-based approach. However, the science of oxidative stress is not described in isolation but in concert with other processes such as apoptosis, cell signaling, and receptor-mediated responses. This approach recognizes that diseases are often multifactorial and oxidative stress is a single component of this.

Diabetes: Oxidative Stress and Dietary Antioxidants, Second Edition is designed for dietitians and nutritionists, food scientists, as well as healthcare workers and research scientists. In this book the target audience also includes diabetologists, biochemists and food scientists, clinicians, basic science researchers, medical students, healthcare industry workers, endocrinologists, family medicine physicians, diabetes nurse practitioners, and drug developers. Contributions are from leading national and international experts including those from world-renowned institutions.

Professor Victor R. Preedy, King's College London 


\title{
Diabetic enteric neuropathy: imbalance between oxidative and antioxidative mechanisms
}

\author{
Nikolett Bódi and Mária Bagyánszki \\ Department of Physiology, Anatomy and Neuroscience, Faculty of Science and Informatics, University of Szeged, \\ Szeged, Hungary
}

\begin{tabular}{ll} 
& \multicolumn{1}{c}{ List of abbreviations } \\
\cline { 2 - 2 } ENS & enteric nervous system \\
HO & heme oxygenase \\
IR & immunoreactive \\
nNOS & neuronal nitric oxide synthase \\
NO & nitric oxide \\
ROS & reactive oxygen species \\
STZ & streptozotocin
\end{tabular}

Structure, function, and diabetic state of the enteric nervous system

The gastrointestinal tract differs from all other organs in that it has an intrinsic nervous system known as the enteric nervous system (ENS). ${ }^{1}$ The ENS has compound functions: controlling the movement of the gastrointestinal tract and gastric acid secretion, regulating movement of fluid across the epithelium and local blood flow, modifying nutrient absorption, interacting with the endocrine and immune systems of the gastrointestinal tract, and maintaining the integrity of the epithelial barrier between the intestinal lumen and tissues within the gut wall. ${ }^{2}$

Enteric neurons, along with the enteric glia cells, are arranged in networks of enteric ganglia connected by interganglionic strands. ${ }^{3}$ The enteric ganglia are organized into two main plexuses in the intestinal wall. The myenteric plexus is between the outer longitudinal and circular muscle layers and extends the full length of the digestive tract from the esophagus to the rectum. The main function of the myenteric plexus is the regulation of the gastrointestinal motility. The submucous plexus is prominent only in the small and large intestines. Submucous ganglia reside in the submucosa tissue layer-in small animals in one layer, in larger animals in two layers. This plexus regulates absorption, blood flow, secretion in the gut wall, and fluid movement between the lumen and the intestinal epithelia. ${ }^{4,5}$

The total number of enteric neurons in humans is 200-600 million, which is approximately equal to the number of neurons in the spinal cord. ${ }^{5}$ Enteric neurons are highly varied in their morphological, neurochemical, and functional properties (Fig. 3.1). Intrinsic primary afferent neurons, interneurons, and motor neurons are all present in the ENS and form local neural circuits in the gastrointestinal tract. ${ }^{4,5}$ The ENS can work autonomously: it communicates bidirectionally with the central nervous system and the other two divisions of the peripheral nervous system-the sympathetic and parasympathetic divisions. This bidirectional connection between the ENS and central nervous system is known as the gut-brain axis. ${ }^{6}$

The enteric glia cells closely associated with the neurons resemble the astrocytes of the central nervous system rather than Schwann cells. In enteric neurons, similarly to the neurons of the central nervous system, several neurotransmitters and neuromodulators are present. Nonadrenergic-noncholinergic neurotransmission, via vasoactive intestinal polypeptide, nitric oxide (NO), and substance $\mathrm{P}$, plays a significant role in the 

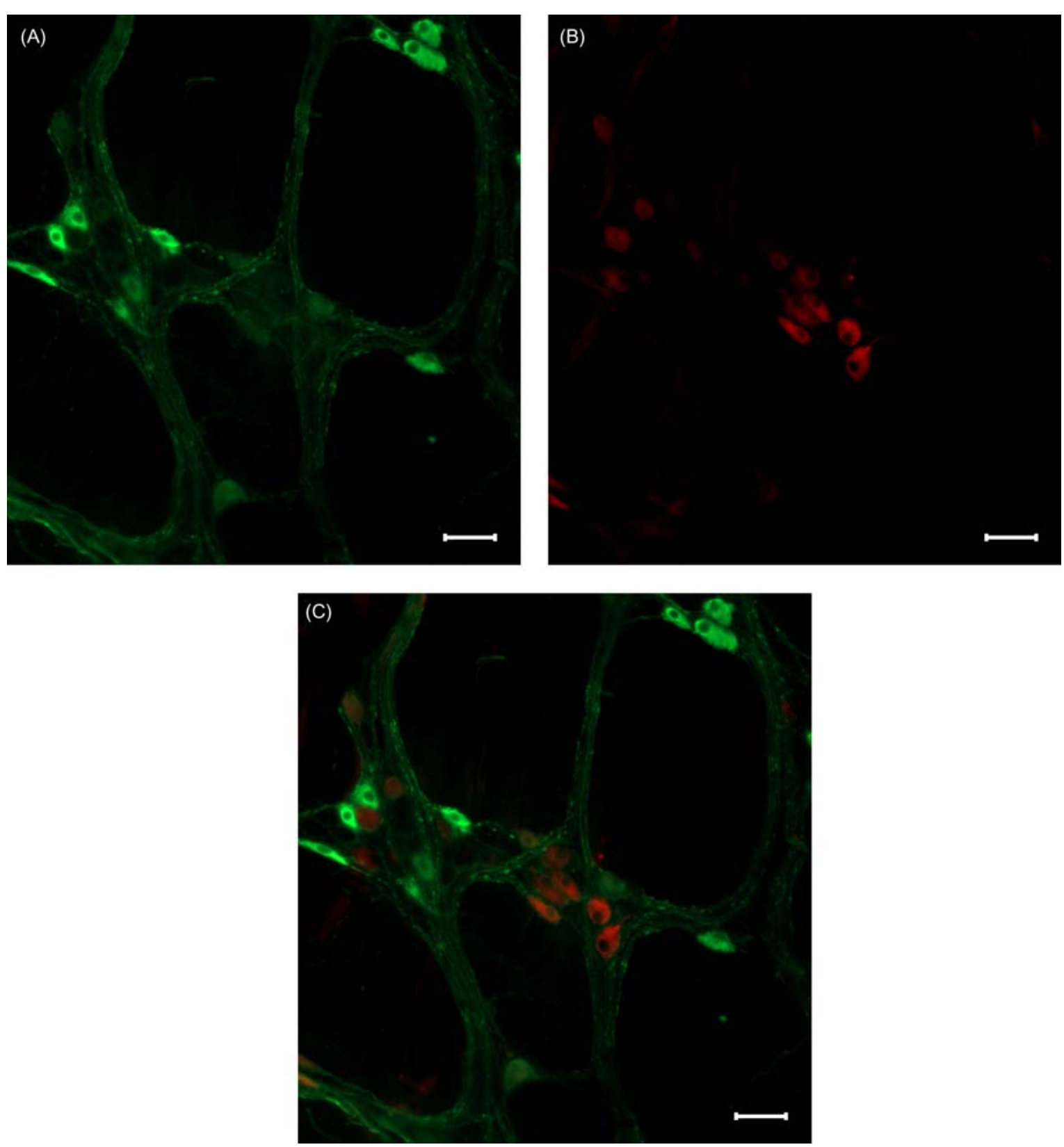

FIGURE 3.1 Photomicrographs of neuronal nitric oxide synthase $(A)$ neurofilament $200(B)$ immunostained myenteric neurons in a whole-mount preparation from the colon of a control rat. Figure $C$ shows the merged pictures. Scale bars: $50 \mu \mathrm{m}$.

peristaltic reflex of the gastrointestinal tract. ${ }^{4,7}$ In nitrergic enteric neurons, NO is produced by the neuronal NO synthase (nNOS) enzyme. The ratio of nitrergic neurons to the total number of neurons is moderate in the submucous plexus, while it is higher in the myenteric ganglia and varies between $25 \%$ and $50 \%$ in the different gut regions and species ${ }^{4,8}$ (Fig. 3.2).

Numerous reports in the literature have suggested that nitrergic myenteric neurons are especially susceptible to neuropathy in different pathological states like alcoholism, ${ }^{9}$ mitochondrial dysfunction, ${ }^{10}$ ischemia, ${ }^{11}$ or diabetes. ${ }^{12-15}$
The review of Cellek et al. discusses two phases of nitrergic enteric neuropathy. ${ }^{15}$ The first phase, with the loss of nNOS in the neurons and nitrergic dysfunction, is reversible on insulin replacement. The second phase is characterized by neuronal apoptosis and is irreversible on insulin replacement. In the past decade it has become clear that the development of the diabetic nitrergic neuropathy is more complicated than suggested earlier ${ }^{15}$ and differs from segment to segment along the gastrointestinal tract. ${ }^{13}$

The imbalance between prooxidant mechanisms and antioxidant defenses contributes to the oxidative 


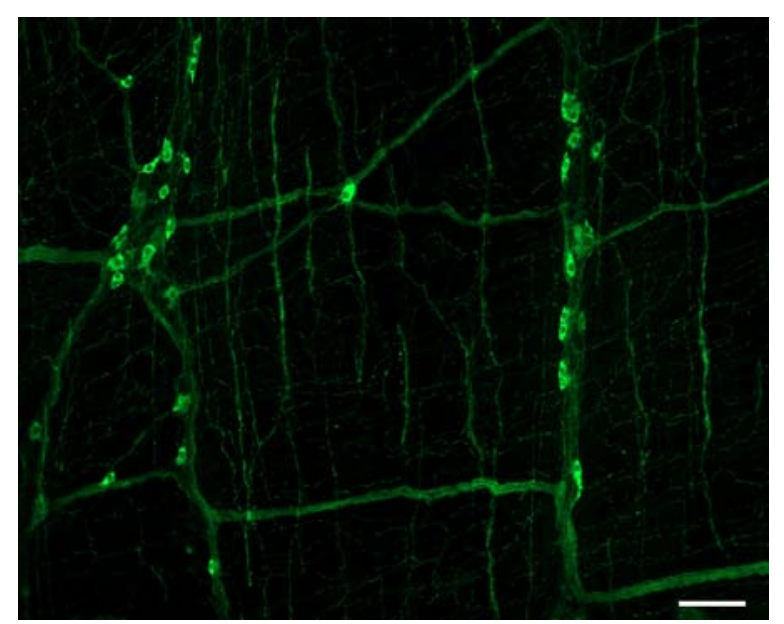

FIGURE 3.2 Photomicrograph of neuronal nitric oxide synthaseimmunostained myenteric neurons in a whole-mount preparation from the duodenum of a control rat. The number of nitrergic neurons in notable in the myenteric plexus. The main function of the nitrergic myenteric neurons is the regulation of the gastrointestinal motility. Scale bar: $100 \mu \mathrm{m}$.

stress in a diabetic state. Elevated oxidative stress is the result of hyperglycemia-induced increased reactive oxygen species (ROS) generation and the impairment of endogenous defenses promoting the pathogenesis of diabetes. Oxidative stress appears to be crucial in diabetes-related enteric neuropathy and gastrointestinal complications. Oxidative stress not only activates different cellular pathways, but also initiates and amplifies neuroinflammation due to the production of proinflammatory cytokines. ${ }^{16}$ Antioxidants have different mechanisms to ameliorate nerve dysfunction in diabetes by acting directly against oxidative damage. ${ }^{17}$

\section{Gut region-specific oxidative environment and antioxidant capacity under physiological conditions}

It is well-known that the different parts of the gastrointestinal tract are anatomically and functionally different. This regionality of the intestinal structure and function develops under strict genetic control ${ }^{18,19}$ and may contribute to the unique features of the enteric neurons under physiological or pathological conditions in different gut segments.

During food consumption, in addition to a range of antioxidants, oxidative agents also enter the body, so the intestine fulfills a critical role in the regulation and maintenance of the antioxidant-prooxidant balance. ${ }^{20,21}$ The appropriate antioxidant defense allows cells to survive in an oxygenated environment. Therefore the redox status of the different gut segments is extremely important in health and in many metabolic diseases. ${ }^{22}$

In the duodenum, an adequate antioxidative environment ensures the normal metabolism of cells. In this particular gut segment in the chicken, high concentrations of vitamin $\mathrm{E}$ were present in the mucosa which decreased toward the ileum and colon. ${ }^{23}$ Similarly, the highest concentrations of carotenoids were observed in duodenal mucosa, with much lower levels in the ileum and colon. ${ }^{23}$ The total antioxidant activity, as well as the superoxide dismutase and catalase activity, was also higher in the rat small intestinal mucosa than in the colon. ${ }^{24}$ Glutathione, which is considered to be an active antioxidant, was found in high concentration in the duodenum. ${ }^{25}$ In addition, the high level of heme oxygenase 1 (HO1) and $\mathrm{HO} 2$ expression in tissue homogenates of the duodenum (originated from the smooth muscle layers and the myenteric plexus) and the high percentage (88\%) of HO1expressing myenteric ganglia in the duodenum, also pointed to a protective basal microenvironment. ${ }^{14}$ Microsomal HO activity was also the highest in the duodenal mucosa, where the absorption of hemoglobin iron is more effective than in the caudal intestinal segments. ${ }^{26}$ Furthermore a number of Lactobacillus species as probiotic strains were observed in high relative abundance in duodenal microbiota originated from luminal content. ${ }^{27-29}$ These findings suggest that as a result of explicit antioxidant capacity of duodenum, the cells located there have greater tolerance and protection against oxidative stress.

Under physiological conditions the expression of the HO proteins is extremely low in the myenteric ganglia of the ileum; only half of the ileal ganglia contained HO1-immunoreactive (IR) neurons and from these ganglia only $16 \%$ contained nNOS-HO1 colocalized neurons. Furthermore, the number of $\mathrm{HO}-\mathrm{IR}$ or nNOS-HO-IR cells was also lowest in the ileum compared to other gut segments. ${ }^{14}$ In correlation with this, others revealed that only $10 \%$ of neurons in the rat ileum $^{30}$ are nNOS-HO2-IR and that HO1 protein expression is hardly detectable in the ileal mucosa. Moreover, it is proved that HO1-IR and HO2-IR neurons are present in very small amounts in the submucous plexus of the small intestine. ${ }^{31}$ The slight expression of these antioxidants may contribute to significantly lower protection against different pathological stimuli in the ileum.

The region-specific excess of bacteria in the gut determines the oxygen supply of the small and large intestine $e^{22,32,33}$ resulting a deep anaerobic state in the distal segments. ${ }^{28}$ For example, in the distal ileum and the colon, the presence of "nonpathogenic" anaerobic bacteria Veillonella sp. has great dominance. ${ }^{27}$ It is also supposed that in the colon, where the baseline redox 
status is far from optimal, the physiological expression of $\mathrm{HO} 1$ and $\mathrm{HO} 2$ is the most pronounced in the colonic myenteric ganglia. ${ }^{14,34}$ As a preconditioning factor, the $\mathrm{HO}$ enzymes are also abundant in the submucous neurons of the colon. ${ }^{31,34}$ Other results also showed $^{32}$ that the colon generates more ROS than does the small intestine, and this prooxidant environment may contribute to greater cancer susceptibility. ${ }^{32}$

\section{Diabetes-related changes in the expression of oxidants and antioxidants in the enteric ganglia of different gut segments}

We have demonstrated that nitrergic myenteric neurons located in different gut segments display different susceptibilities to diabetic damage (Fig. 3.3) and insulin treatment. ${ }^{13,35}$ These findings emphasize the importance of the neuronal microenvironment along the gastrointestinal tract in the pathogenesis of diabetic nitrergic neuropathy and urge investigation of the underlying molecular mechanisms, like region-specific intestinal ROS accumulation and endogenous antioxidant distribution.

Recent studies ${ }^{14,36}$ have demonstrated evidence for gut region-specific accumulation of ROS, and have also shown that enhanced oxidative stress leads to regionally distinct activation of endogenous antioxidants in the different intestinal segments of rats with streptozotocin (STZ)-induced diabetes (Fig. 3.4).

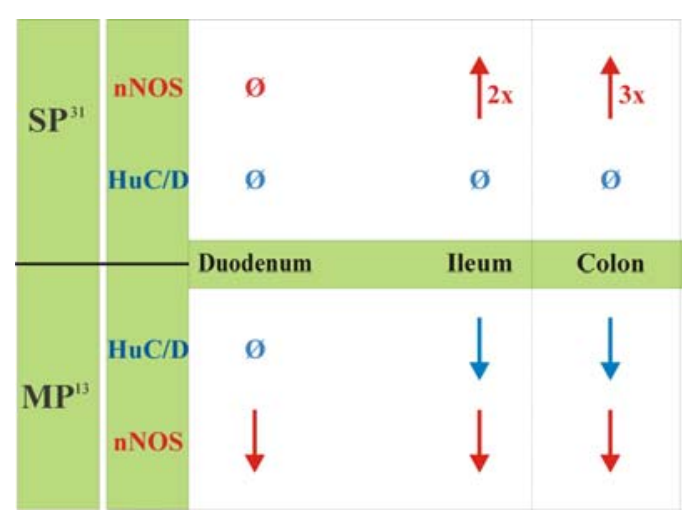

FIGURE 3.3 Density of total and nitrergic neurons in the two enteric plexuses and different intestinal regions of diabetic rats. The number of total and nitrergic neurons varied differently in the submucous and myenteric plexuses (SP and MP) of diabetics. The total number of submucous neurons was not affected in the different gut segments, while with the exception of the duodenal ganglia, the number of nitrergic neurons was increased significantly in the ileum and colon by diabetes. In the myenteric ganglia, a gut region-specific decrease in total and nitrergic neuronal density was demonstrated. Summarized from Bódi et al. (2017) ${ }^{31}$ and Izbéki et al. (2008). ${ }^{13}$ $\mathrm{HuC} / \mathrm{D}$ is a pan-neuronal marker of enteric neurons; nNOSneuronal nitric oxide synthase.

\section{Duodenum}

In our study, in the duodenum of type 1 diabetic rats, the number of nitrergic myenteric neurons decreased, while the total neuronal number was not altered, suggesting that only the neurochemical character of the cells changed and no apoptosis occurred..$^{13}$ Coincidentally, there were no significant changes in the production of a powerful oxidant, peroxynitrite, whereas the mRNA level of the free radical scavenger metallothionein-2 increased $\sim 300$-fold in this particular gut segment. Additionally, 2.5-3fold elevated glutathione levels were revealed in the duodenal tissues of diabetics, which may protect cellular proteins against oxidation, directly detoxify $\mathrm{ROS}$, and play a remarkable role to maintain the optimal thiol/redox balance. ${ }^{36}$ Moreover, the highest level of $\mathrm{HO} 1$ and $\mathrm{HO} 2$ expression in tissue homogenates of control duodenum also emphasizes a highly protective microenvironment in this intestinal segment. ${ }^{14}$ It is assumed that due to the adequate oxidative environment, the nitrergic neurons receive greater protection and can better tolerate hyperglycemia-related oxidative stress in the duodenum. In this gut segment, besides a decrease in the number of nNOS neurons, the number of nNOS-HO colocalized myenteric neurons was not altered significantly. This suggests that

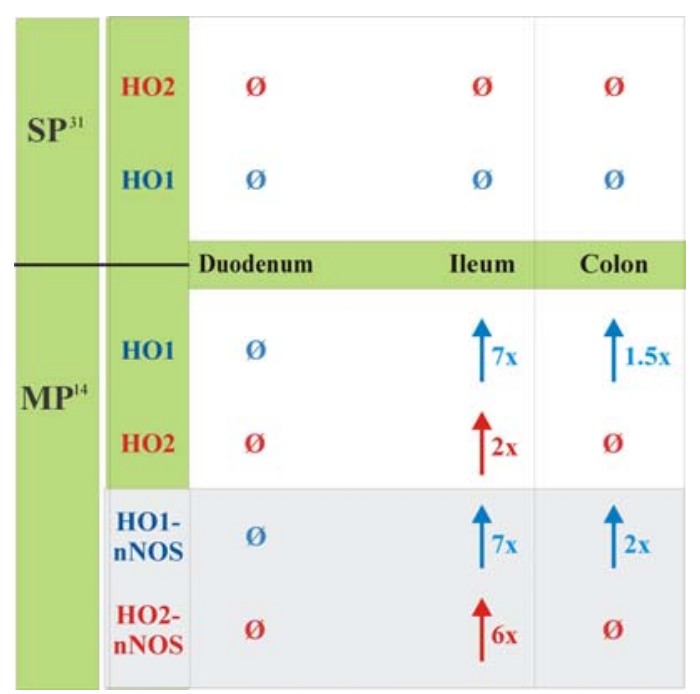

FIGURE 3.4 Expression of endogenous heme oxygenase 1 and 2 in the two enteric plexuses and different intestinal regions of diabetic rats. In diabetics, the number of heme oxygenase (HO) 1 and $\mathrm{HO} 2-$ immunoreactive neurons did not change significantly in the submucous plexus (SP) of different intestinal segments compare to controls. However, in the myenteric plexus (MP) of diabetic rats, the number of HO1- and HO2-positive neurons, as well as the number of those neurons in which the $\mathrm{HO}$ is colocalized with neuronal nitric oxide synthase (HO1-nNOS and HO2-nNOS) increased significantly in the ileum and colon, but not in the duodenum. Summarized from Bódi et al. (2017) $)^{31}$ and Chandrakumar et al. (2017). ${ }^{14}$ 
HO-containing nitrergic neurons are less affected by diabetic damage. ${ }^{14}$

Previous studies have shown that diabetic impairments of the intestinal microbiota contribute to the imbalance between the accumulation of reactive radicals and endogenous antioxidant defenses. ${ }^{37-39}$ In our study with STZ-induced diabetic rats, using next-generation DNA sequencing, the duodenal microbiota did not display the development of a disadvantageous environment. Moreover, in the microbial community of the diabetic duodenum, $49 \%$ of the total reads were due to the order Lactobacillales (including almost all members of the genus Lactobacillus), relative to $31 \%$ in healthy controls. ${ }^{28}$ The increased number of lactic acid bacteria strains, the key players of probiotics, results in enhanced antioxidant capacity in different ways (e.g., these probiotics produce antioxidant metabolites, regulate different signaling pathways, downregulate activities of ROS-producing enzymes, or improve the absorption of antioxidants and reduce postprandial lipid concentrations). ${ }^{29,40}$ It has also been observed that consumption of these probiotics presented higher activity of superoxide dismutase and glutathione peroxidase in diabetic patients relative to controls. ${ }^{41}$

The appropriate intracellular glutathione level is important to maintain a proper intestinal $\mathrm{Ca}^{2+}$ absorption. ${ }^{42,43}$ It appears that the duodenum is the main site of that because the lowest $\mathrm{pH}$ of the gut with decreasing absorption rate to distal part. ${ }^{44}$ In mice on a high-fat diet, increased oxidative stress and redox imbalance was revealed in the duodenum, resulting in the inhibition of calcium absorption and related gene expression. ${ }^{45}$ Similarly, in STZ-induced diabetic rats, it was also demonstrated that intestinal oxidative stress at early stages of diabetes leads to an inhibited $\mathrm{Ca}^{2+}$ absorption. However, time-dependent adaptive mechanisms contribute to normalizing the intestinal $\mathrm{Ca}^{2+}$ absorption, as well as the duodenal redox state. ${ }^{43,46}$

\section{Ileum}

In the diabetic ileum, not only did the density of nitrergic myenteric neurons decrease, but so did the total number of neurons. . $^{13,35,47}$ In this particular gut segment, the markers of oxidative stress caused by constant hyperglycemia were markedly expressed. The level of malondialdehyde, an end product of lipid peroxidation, was almost doubled, while the levels of antioxidant molecules, such as superoxide dismutase, catalase, and glutathione, were significantly lower in ileal tissue homogenates of diabetic rats compared to controls. ${ }^{48}$ Similarly, significantly increased lipid peroxidation and protein oxidation was observed in another study using diabetic rats. ${ }^{49}$
Shotton and Lincoln ${ }^{50}$ have demonstrated an increased cell body size of nNOS-IR neurons in diabetes, while HO2-IR neurons were not affected. Moreover, the double-labeling studies revealed that the diabetes-related alteration in size of perikarya was confined to those nNOS-IR neurons that did not contain $\mathrm{HO} 2$; those nitrergic neurons were protected against diabetic effects, in which nNOS and $\mathrm{HO} 2$ were colocalized. Interestingly, compared to the extremely low presence of the $\mathrm{HO}$ proteins in controls, all of the ileal ganglia included HO1-IR neurons and more than $60 \%$ of them were also IR for nNOS in diabetic rats. The greatest increase in the ratio of nNOS-HO2-IR ganglia was also shown in the ileum of diabetics ${ }^{14}$ compared to other intestinal regions. Furthermore, both the HO1- and the nNOS-HO1-IR neuronal number was enhanced sevenfold, and the number of nNOS-HO2-IR neurons increased sixfold in the diabetic ileum ${ }^{14}$ compared to controls. This data supports that many of the nitrergic neurons start to produce $\mathrm{HO}$ enzymes and suggests that those nNOS-positive neurons which are not colocalized with $\mathrm{HOs}$ will be injured by diabetes.

Based on these findings, the highest increase in expression of the endogenous $\mathrm{HO}$ system and the colocalization of $\mathrm{HO} 1$ and $\mathrm{HO} 2$ with nNOS in myenteric neurons was observed in the ileum of diabetics, which highlights the outstanding concern of this intestinal segment in diabetes-related damage. This remarkable diabetic involvement of the ileum was also predicted in our earlier study. ${ }^{28}$ We demonstrated that only the diabetic ileal feces samples exhibited a massive (more than 30\%) Klebsiella invasion. ${ }^{28}$ Accumulation of these pathogens results in gut inflammation, leaky epithelium and easy paths for bacteria through the intestinal tissues, developing a pathological microenvironment and impairment of gut immunity. ${ }^{51}$ It is assumed that diabetes-related explicit changes in the microbial composition of the ileum ${ }^{28}$ may contribute to the elevated mucosal immune response and the greatest induction of endogenous $\mathrm{HO}$ defenses in this segment. It was also reported that intestinal HO1 is induced by the enteric microbiota and regulates macrophage activity, ${ }^{52}$ which emphasizes even further the importance of a disturbed enteric microbiota in the determination of intestinal redox status. Ileal microbiota dysbiosis is responsible for the glucagon-like peptide-1 resistance, and therefore obstructs glucagonlike peptide-1-induced NO production by enteric neurons and induces enteric neuropathy in diabetic mice. ${ }^{53}$

\section{Colon}

In the colon of diabetic rats, both the nitrergic and the total neuronal number decreased significantly. ${ }^{13,35}$ 


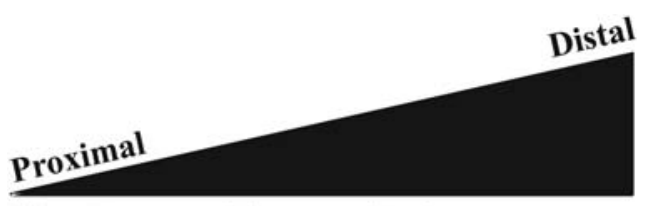

(A) Vulnerability to oxidative stress

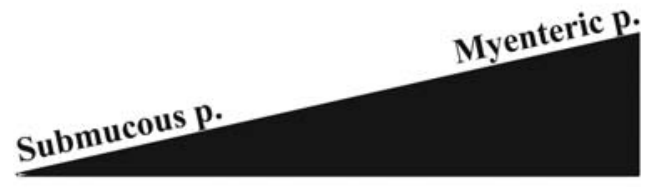

(B) Vulnerability to oxidative stress

FIGURE 3.5 Vulnerability of the gut and enteric plexuses to diabetes-related oxidative stress. The distal part of the gut is more vulnerable than the proximal to diabetic oxidative stress (A). While myenteric neurons are more susceptible to diabetic damage, the submucous ganglia have greater resistance against hyperglycemiainduced oxidative stress (B). p-plexus.

In correlation with this myenteric cell loss, peroxynitrite production was doubled. Superoxide dismutase activity decreased, whereas glutathione level, catalase activity, and metallothionein-2 expression were not significantly changed in the large intestine of diabetic animals. ${ }^{36}$ The level of metallothionein-1 mRNA was increased sevenfold in the colon. In the colon of diabetics, the presence of severe necrosis was also confirmed by electron microscopy. ${ }^{36}$ These data further suggest that the distal part of the gut is the most vulnerable segment to oxidative stress (Fig. 3.5A).

The proportion of nNOS-IR neurons colocalizing with HO1 exhibited a threefold increase $(72 \%$ vs. $23 \%$ ) and the ratio of nNOS-IR neurons colocalizing with $\mathrm{HO} 2$ was also enhanced $(68 \%$ vs. $44 \%)$ in the colon of diabetics. ${ }^{14}$ Besides a $22 \%$ decrease in the nNOS neuronal number, a more than $50 \%$ increase was demonstrated in the number of nNOS-HO1-IR neurons, while the number of nNOS-HO2-IR neurons did not alter significantly compared to controls. This suggests that HO-containing nitrergic neurons enjoy higher protection, while those that do not contain $\mathrm{HO}$ are heavily affected by diabetic damage.

Bacterial dysbiosis was also demonstrated in the large intestinal segment of diabetics in our study. ${ }^{28}$ Regarding the microbial composition of the diabetic colon, the major representatives belonged to the genus Klebsiella. The relative abundance of $6 \%$ of this genus was significantly less than that reported in the diabetic ileum, but still noteworthy compared to the controls. ${ }^{28}$ This observed increase in the level of the pathogen Klebsiella could be associated with intestinal inflammation and enteric neuropathy.

\section{Submucous ganglia}

The involvement of different myenteric neuronal populations in diabetic oxidative injuries has been thoroughly investigated in human and animal models. However, the responsiveness of submucous neurons to diabetic damage and the state of their antioxidant defenses is poorly studied. It has been recently demonstrated that the total number of submucous neurons was not affected by diabetes in different segments of the small and large intestine. ${ }^{31,54}$ These findings suggest greater resistance of submucous neurons against hyperglycemia-induced oxidative stress ${ }^{31,55}$ (Fig. 3.5B). The density of the nitrergic submucous population did not vary in the different intestinal segments. ${ }^{31,56}$ In the duodenal submucous ganglia, the number of nitrergic neurons was not affected by diabetic state. However, in the ileum and colon, it increased significantly, presumingly due to modifications of neurochemical coding as an answer to diabetic oxidative damage (Fig. 3.3). Increased immunoreactivity in vasoactive intestinal polypeptide-positive neurons in the submucous plexus has also been revealed in diabetes. ${ }^{57}$ Treatment with different antioxidant agents, like ascorbic acid or quercetin proved to be neuroprotective against these diabetes-related alterations. ${ }^{55,57}$ The distribution of HO1-IR and HO2-IR submucous neurons were more pronounced in the large intestine (about $50 \%)$ than in the small intestinal segments $(0 \%-5 \%)$ in healthy controls. Chronic hyperglycemia did not result in any significant changes in HO-immunoreactivity in these segments, while these neurons had intestinal region-dependent responsiveness to immediate insulin treatment. ${ }^{31}$ As colocalization of nNOS-HO2 in submucous neurons was observed in other studies, ${ }^{34,58}$ drawing attention to its protective capacity, the endogenous HOs may contribute to the elevated number of nitrergic submucous neurons in the distal part of the gut, which requires further studies.

\section{Conclusion and perspectives}

Considering the above-mentioned results, the imbalance between oxidative and antioxidative mechanisms in diabetes intensely contributes to enteric neuropathy in the gastrointestinal tract. It is also important to emphasize that the two enteric plexuses are affected by the hyperglycemia-related oxidative stress differently and in a strictly gut region-specific manner (Fig. 3.6).

Further highlighting the importance of oxidative and antioxidative imbalance, other studies show that oxidative stress plays a pivotal role in pathological states where the gastrointestinal tract is injured, like 
Oxidative stress

No changes in peroxynitrite production ${ }^{36}$
Antioxidant defence

Duodenum Metallothionein mRNA ${ }^{36}$ Glutathione $\uparrow^{36}$

HO-containing nitrergic neurons are less damaged ${ }^{14}$

Higher representation of order Lactobacillales ${ }^{28}$

\begin{tabular}{|c|c|c|}
\hline $\begin{array}{l}\text { Lipid peroxidation } \uparrow^{48,49} \\
\text { Protein oxidation } \uparrow^{49} \\
\text { Klebsiella invasion } \\
\text { Microbiota dysbiosis } \\
\text { Mes,53 }^{28}\end{array}$ & Ileum & $\begin{array}{l}\text { Superoxide dismutase, } \\
\text { catalase, glutathione } \downarrow^{48} \\
\text { Greatest induction of } \\
\text { HO1 and HO2 expression } \\
\text { in nitrergic neurons }{ }^{14}\end{array}$ \\
\hline $\begin{array}{l}\text { Peroxynitrite } \uparrow^{36} \\
\text { Microbiota dysbiosis }{ }^{28}\end{array}$ & Colon & $\begin{array}{l}\text { Superoxide dismutase } \downarrow^{36} \\
\text { Catalase, glutathione } \boldsymbol{\emptyset}^{36} \\
\text { Metallothionein } 1 \text { mRNA } \uparrow^{36} \\
\text { Induction of HO system } \\
\text { in nitrergic neurons }\end{array}$ \\
\hline
\end{tabular}

FIGURE 3.6 Diabetes-related changes of oxidative stress markers and antioxidant defense mechanisms in the different gut segments. In the diabetic duodenum, besides the elevated levels of antioxidant enzymes, the higher abundance of the order Lactobacillales was observed. In contrast, enhanced lipid peroxidation, protein oxidation, a massive invasion of pathogens, Klebsiella and microbial dysbiosis were demonstrated in the distal part of the gut. In addition, the greatest induction of the endogenous heme oxygenase (HO) system was revealed in the ileum and colon.

gut inflammation, aging, ${ }^{7}$ gastrointestinal mucosal disease, $^{59}$ or alcoholism. ${ }^{60}$

Recent data have elucidated that the gut microbiota is a key contributor to the pathophysiological effects of the gut-brain axis. ${ }^{6}$ Therefore the imbalance between oxidative elements and antioxidant defenses not only has an important local effect in the gastrointestinal tract, but also has a unique function in the development of neurodegenerative or neuropsychological disorders.

\section{Summary points}

- Nitrergic myenteric neurons in different gut segments display different susceptibilities to diabetic damage and to insulin treatment, emphasizing the importance of the neuronal microenvironment in the pathogenesis of diabetic neuropathy.

- Shifts in the balance between the production and scavenging of free radicals lead to region-specific oxidative stress in the gut, which in turn contribute to enteric neuropathy in diabetes.

- Both the accumulation of reactive oxygen species and the activation of endogenous antioxidants show distinct regional differences in diabetes.
- The distal part of the small intestine shows greater changes to oxidative stress than the proximal part.

- Nitrergic neurons that contain heme oxygenase enjoy higher protection while those that do not contain heme oxygenase are heavily affected by oxidative damage.

- Microbial dysbiosis demonstrated in the distal part of the gut may contribute to inducing endogenous heme oxygenase defense mechanisms in the ileum and colon.

\section{References}

1. Furness JB. The enteric nervous system. Oxford: Blackwell Publishing; 2006.

2. Furness JB. The enteric nervous system and neurogastroenterology. Nat Rev Gastroenterol Hepatol 2012;9:286-94.

3. Costa M, Brookes SJH, Hennig GW. Anatomy and physiology of the enteric nervous system. Gut 2000;47(Suppl. IV):iv15-19.

4. Furness JB. Types of neurons in the enteric nervous system. I Auton Nerv Syst 2000;81:87-96.

5. Furness JB, Callaghan BP, Rivera LR, Cho HJ. The enteric nervous system and gastrointestinal innervation: integrated local and central control. Adv Exp Med Biol 2014;817:39-71.

6. Mittal R, Debs LH, Patel AP, Nguyen D, Patel K, O'Connor G, et al. Neurotransmitters: the critical modulators regulating gutbrain axis. J Cell Physiol 2017;232:2359-72.

7. Nezami BG, Srinivasan S. Enteric nervous system in the small intestine: pathophysiology and clinical implications. Curr Gastroenterol Rep 2010;12:358-65.

8. Bódi N, Battonyai I, Talapka P, Fekete É, Bagyánszki M. Spatial pattern analysis of nitrergic neurons in the myenteric plexus of the duodenum of different mammalian species. Acta Biol Hung 2009;60:347-58.

9. Bagyánszki M, Torfs P, Krecsmarik M, Fekete É, Adriaensen D, Van Nassauw L, et al. Chronic alcohol consumption induces an overproduction of NO by nNOS- and iNOS-expressing myenteric neurons in the murine small intestine. Neurogastroenterol Motil 2011;23:e237-48.

10. Viader A, Wright-Jin EC, Vohra BP, Heuckeroth RO, Milbrandt J. Differential regional and subtype-specific vulnerability of enteric neurons to mitochondrial dysfunction. PLoS One 2011;6: e27727.

11. Rivera LR, Thacker M, Pontell L, Cho HJ, Furness JB. Deleterious effects of intestinal ischemia/reperfusion injury in the mouse enteric nervous system are associated with protein nitrosylation. Cell Tissue Res 2011;344:111-23.

12. Cellek S, Qu W, Schmidt AM, Moncada S. Synergistic action of advanced glycation end products and endogenous nitric oxide leads to neuronal apoptosis in vitro: a new insight into selective nitrergic neuropathy in diabetes. Diabetologia 2004;47:331-9.

13. Izbéki F, Wittman T, Rosztóczy A, Linke N, Bódi N, Fekete E, et al. Immediate insulin treatment prevents gut motility alterations and loss of nitrergic neurons in the ileum and colon of rats with streptozotocin-induced diabetes. Diabetes Res Clin Pract 2008;80:192-8

14. Chandrakumar L, Bagyánszki M, Szalai Z, Mezei D, Bódi N. Diabetes-related induction of the heme oxygenase system and enhanced colocalization of heme oxygenase 1 and 2 with neuronal nitric oxide synthase in myenteric neurons of different intestinal segments. Oxid Med Cell Longev 2017;2017:1890512.

15. Cellek S, Foxwell NA, Moncada S. Two phases of nitrergic neuropathy in streptozotocin-induced diabetic rats. Diabetes 2003;52:2353-62. 
16. Sandireddy R, Yerra VG, Areti A, Komirishetty P, Kumar A. Neuroinflammation and oxidative stress in diabetic neuropathy: futuristic strategies based on these targets. Int J Endocrinol 2014;2014:674987.

17. Oyenihi AB, Ayeleso AO, Mukwevho E, Masola B. Antioxidant strategies in the management of diabetic neuropathy. Biomed Res Int 2015;2015:515042.

18. Burns AJ, Pachnis V. Development of the enteric nervous system: bringing together cells, signals and genes. Neurogastroenterol Motil 2009;1:100-2.

19. Doodnath R, Wride M, Puri P. The spatiotemporal patterning of Hoxa9 and Hoxa13 in the developing zebrafish enteric nervous system. Pediatr Surg Int 2012;28:115-21.

20. Halliwell B, Zhao K, Whiteman M. The gastrointestinal tract: a major site of antioxidant action? Free Radic Res 2000;33:819-30.

21. Surai PF, Fisinin VI. Antioxidant-prooxidant balance in the intestine: applications in chick placement and pig. Weaning J Veter Sci Med 2015;3(16).

22. Circu ML, Aw TY. Redox biology of the intestine. Free Radic Res 2011;45:1245-66.

23. McLean JA, Karadas F, Surai PF, McDevitt RM, Speake BK. Lipid-soluble and water-soluble antioxidant activities of the avian intestinal mucosa at different sites along the intestinal tract. Comp Biochem Physiol B Biochem Mol Biol 2005;141:366-72.

24. Blau S, Rubinstein A, Bass P, Singaram C, Kohen R. Differences in the reducing power along the rat GI tract: lower antioxidant capacity of the colon. Mol Cell Biochem 1999;194:185-91.

25. Loguercio C, Di Pierro M. The role of glutathione in the gastrointestinal tract: a review. Ital J Gastroenterol Hepatol 1999;31:401-7.

26. Raffin SB, Woo CH, Roost KT, Price DC, Schmid R. Intestinal absorption of hemoglobin iron-heme cleavage by mucosal heme oxygenase. J Clin Invest 1974;54:1344-52.

27. Zilberstein B, Quintanilha AG, Santos MA, Pajecki D, Moura EG, Alves PR, et al. Digestive tract microbiota in healthy volunteers. Clin (Sao Paulo) 2007;62:47-54.

28. Wirth R, Bódi N, Maróti G, Bagyánszki M, Talapka P, Fekete É, et al. Regionally distinct alterations in the composition of the gut microbiota in rats with streptozotocin-induced diabetes. PLoS One 2014;9:e110440.

29. Wang $Y$, Wu Y, Wang $Y, X u$ H, Mei X, Yu D, et al. Antioxidant properties of probiotic bacteria. Nutrients 2017;9 E521.

30. Donat ME, Wong K, Staines WA, Krantis A. Heme oxygenase immunoreactive neurons in the rat intestine and their relationship to nitrergic neurons. J Auton Nerv Syst 1999;77:4-12.

31. Bódi N, Szalai Z, Chandrakumar L, Bagyánszki M. Regiondependent effects of diabetes and insulin-replacement on neuronal nitric oxide synthase- and heme oxygenase-immunoreactive submucous neurons. World J Gastroenterol 2017;23:7359-68.

32. Sanders LM, Henderson CE, Hong MY, Barhoumi R, Burghardt RC, Carroll RJ, et al. Pro-oxidant environment of the colon compared to the small intestine may contribute to greater cancer susceptibility. Cancer Lett 2004;208:155-61.

33. Eckburg PB, Bik EM, Bernstein CN, Purdom E, Dethlefsen L, Sargent M, et al. Diversity of the human intestinal microbial flora. Science 2005;308:1635-8.

34. Battish R, Cao GY, Lynn RB, Chakder S, Rattan S. Heme oxygenase-2 distribution in anorectum: colocalization with neuronal nitric oxide synthase. Am J Physiol Gastrointest Liver Physiol 2000;278:G148-55.

35. Bagyánszki M, Bódi N. Diabetes-related alterations in the enteric nervous system and its microenvironment. World J Diabetes 2012;3:80-93.

36. Jancsó Z, Bódi N, Borsos B, Fekete É, Hermesz E. Gut regionspecific accumulation of reactive oxygen species leads to regionally distinct activation of antioxidant and apoptotic marker molecules in rats with STZ-induced diabetes. Int $J$ Biochem Cell Biol 2015;62:125-31.

37. Gomes AC, Bueno AA, de Souza RG, Mota JF. Gut microbiota, probiotics and diabetes. Nutr J 2014;13:60.

38. Mardinoglu A, Shoaie S, Bergentall M, Ghaffari P, Zhang C, Larsson E, et al. The gut microbiota modulates host amino acid and glutathione metabolism in mice. Mol Syst Biol 2015;11:834.

39. Lombardi VC, De Meirleir KL, Subramanian K, Nourani SM, Dagda RK, Delaney SL, et al. Nutritional modulation of the intestinal microbiota; future opportunities for the prevention and treatment of neuroimmune and neuroinflammatory disease. J Nutr Biochem 2018;61:1-16.

40. Mikelsaar M, Zilmer M. Lactobacillus fermentum ME-3-an antimicrobial and antioxidative probiotic. Microb Ecol Health Dis 2009;21:1-27.

41. Ejtahed HS, Mohtadi-Nia J, Homayouni-Rad A, Niafar M, Asghari-Jafarabadi M, Mofid V. Probiotic yogurt improves antioxidant status in type 2 diabetic patients. Nutrition 2012;28:539-43.

42. Tolosa de Talamoni N, Marchionatti A, Baudino V, Alisio A. Glutathione plays a role in the chick intestinal calcium absorption. Comp Biochem Physiol A Physiol 1996;115:127-32.

43. Rivoira M, Rodríguez V, López MP, Tolosa de Talamoni N. Time dependent changes in the intestinal $\mathrm{Ca}^{2+}$ absorption in rats with type I diabetes mellitus are associated with alterations in the intestinal redox state. Biochim Biophys Acta 2015;1852 (3):386-94.

44. Wasserman RH. Vitamin D and the dual processes of intestinal calcium absorption. J Nutr 2004;134:3137-9.

45. Xiao Y, Cui J, Shi YH, Sun J, Wang ZP, Le GW. Effects of duodenal redox status on calcium absorption and related genes expression in high-fat diet-fed mice. Nutrition 2010;26:1188-94.

46. Diaz de Barboza G, Guizzardi S, Moine L, Tolosa de Talamoni N. Oxidative stress, antioxidants and intestinal calcium absorption. World J Gastroenterol 2017;23:2841-53.

47. Pereira RV, Tronchini EA, Tashima CM, Alves EP, Lima MM, Zanoni JN. L-glutamine supplementation prevents myenteric neuron loss and has gliatrophic effects in the ileum of diabetic rats. Dig Dis Sci 2011;56:3507-16.

48. Kochar NI, Umathe SN. Beneficial effects of L-arginine against diabetes-induced oxidative stress in gastrointestinal tissues in rats. Pharmacol Rep 2009;61:665-72.

49. Shirpoor A, Ansari MH, Salami S, Pakdel FG, Rasmi Y. Effect of vitamin $\mathrm{E}$ on oxidative stress status in small intestine of diabetic rat. World J Gastroenterol 2007;13:4340-4.

50. Shotton HR, Lincoln J. Diabetes only affects nitric oxide synthase-containing myenteric neurons that do not contain heme oxygenase 2. Brain Res 2006;1068:248-56.

51. Vaarala O, Atkinson MA, Neu J. The "perfect storm" for type 1 diabetes. The complex interplay between intestinal microbiota, gut permeability, and mucosal immunity. Diabetes 2008;57:2555-62.

52. Onyiah JC, Sheikh SZ, Maharshak N, Otterbein LE, Plevy SE. Heme oxygenase- 1 and carbon monoxide regulate intestinal homeostasis and mucosal immune responses to the enteric microbiota. Gut Microbes 2014;5:220-4.

53. Grasset E, Puel A, Charpentier J, Collet X, Christensen JE, Tercé $\mathrm{F}$, et al. A specific gut microbiota dysbiosis of type 2 diabetic mice induces GLP-1 resistance through an enteric NOdependent and gut-brain axis mechanism. Cell Metab 2017;25 1075-1090.e5.

54. da Silva GG, Zanoni JN, Buttow NC. Neuroprotective action of Ginkgo biloba on the enteric nervous system of diabetic rats. World J Gastroenterol 2011;17:898-905. 
55. Lopes CR, Ferreira PE, Zanoni JN, Alves AM, Alves EP, Buttow NC. Neuroprotective effect of quercetin on the duodenum enteric nervous system of streptozotocin-induced diabetic rats. Dig Dis Sci 2012;57(12):3106-15.

56. Chino Y, Fujimura M, Kitahama K, Fujimiya M. Colocalization of NO and VIP in neurons of the submucous plexus in the rat intestine. Peptides 2002;23:2245-50.

57. Zanoni JN, Hernandes L, Bazotte RB, Miranda Neto MH. Terminal ileum submucous plexus: study of the VIP-ergic neurons of diabetic rats treated with ascorbic acid. Arq Neuropsiquiatr 2002;60:32-7.
58. Miller SM, Reed D, Sarr MG, Farrugia G, Szurszewski JH. Haem oxygenase in enteric nervous system of human stomach and jejunum and co-localization with nitric oxide synthase. Neurogastroenterol Motil 2001;13:121-31.

59. Bhattacharyya A, Chattopadhyay R, Mitra S, Crowe SE. Oxidative stress: an essential factor in the pathogenesis of gastrointestinal mucosal diseases. Physiol Rev 2014;94:329-54.

60. Bagyánszki M, Bódi N. Gut region-dependent alterations of nitrergic myenteric neurons after chronic alcohol consumption. World J Gastrointest Pathophysiol 2015;6:51-7. 
This page intentionally left blank 